\title{
Remodeling of Extracellular Matrix Protein, Collagen by Beta-Adrenoceptor Stimulation and Denervation in Mouse Gastrocnemius Muscle
}

\author{
Rakesh KUMAR and Sushma SHARMA \\ Department of Biosciences, Himachal Pradesh University, Summer Hill, Shimla 171005 India
}

\begin{abstract}
A chronic administration of isoproterenol hydrochloride ( $60 \mathrm{mg} / \mathrm{kg}$ body weight; 30 days) alters the collagen metabolism in denervated gastrocnemius muscle of mice. Hydroxyproline assay for collagen showed an increase in collagen content by $47 \%, 44 \%$, and $61 \%$ in innervated gastrocnemius + drug, denervated control, and denervated + drug, respectively, in gastrocnemius muscles after 30 days of drug administration. Collagen proliferation is $\beta$-agonist (isoproterenol) specific confirmed with the simultaneous administration of $\beta$-antagonist propranolol (100 mg/kg body weight; 30 days). Van Gieson staining showed heavy collagen proliferation in the epimysium region of the muscle section and adventitia of blood vessels and some specialized regions. However, denervated gastrocnemius
\end{abstract}

muscle represented a heavy collagen proliferation in the endomysium region, which also is probably responsible for extensive collagen proliferation in denervated muscle after drug administration. The SDS-PAGE of pepsin-soluble collagen revealed five bands from origin to the point of migration, $\gamma, \beta_{1}$, $\beta_{2}, \alpha_{1}$, and $\alpha_{2}$. The SDS-PAGE of CNBr-treated pepsin-insoluble collagen pointed toward the more prominent remodeling of collagen metabolism in the $\beta$-agonist-induced denervated gastrocnemius muscle after drug administration. From the present study, we can conclude that $\beta$-agonist, isoproterenol hydrochloride, augments collagen proliferation in innervated as well as in denervated gastrocnemius muscle.

Key words: $\beta$-adrenergic agonist, isoproterenol, collagen, gastrocnemius, extracellular matrix, denervation atrophy.

$\beta_{\text {-adrenergic receptor agonists can induce hypertrophy }}$ of striated muscles and may also lead to the development of a faster contracting muscle phenotype [1]. The trophic effect of $\beta$-adrenoceptor agonists may also benefit patients with chronic heart failure by counteracting the associated loss of muscle mass. For similar reasons, competitive and recreational athletes and bodybuilders have long used $\beta$-adrenoceptor agonists in their search for enhanced performance [2]. The illicit use of these agents persists to the present day [3]. However, the administration of agonists does not necessarily lead to improved muscle performance [4-8]. A chronic administration of these drugs to denervated rats not only limits but goes on to reverse denervation atrophy $[9,10]$. Denervation atrophy is conspicuously accompanied by fibrosis and proliferation of noncontractile connective tissue in extracellular spaces. However, what happens to proliferating connective tissue in denervated muscle during beta agonist therapy remains largely unknown.

Studies on skeletal muscle have traditionally been focused on myosin and actin. However, muscle secretes a network of macromolecules termed the extracellular matrix (ECM). Its proteins form important structural and functional components of muscle tissue and are thought to provide it with stiffness and to regulate its compliance. The extracellular matrix (ECM) is formed by complex molecular networks, which determine the architecture of a tissue and regulate various biological processes [11, 12]. Skeletal muscle ECM is organized in three levels: the epimysium surrounds the entire skeletal muscle, the perimysium surrounds muscle bundles consisting of a variable number of muscle cells, and the endomysium outlines the individual muscle fibers [13]. The most abundant structural component of ECM is collagens.

Skeletal muscle predominantly contains collagen type I and type III proteins within the extracellular matrix of skeletal muscle, and they are responsible for tissue fibrotic response during the pathophysiological state. Collagen I and III are fibril forming and serve as a supportive structure in muscle tissue. The cross-link between collagen fibrils are largely responsible for the tensile strength attributed to collagen. The cross-linking of collagen alters tissue structure and function because of toughness and reduced tissue elasticity $[14,15]$. Variability in the collagen contents of skeletal muscle therefore influences tissue contractile responses. The purpose of the present study is to investigate collagen turnover in gastrocnemius skeletal muscle within conditions causing muscle denervation at-

Received on Dec 2, 2005; accepted on Jan 29, 2006; released online on Feb 23, 2006; DOI: 10.2170/physiolsci.RP002205 Correspondence should be addressed to: Sushma Sharma, Department of Biosciences, Himachal Pradesh University, Summer Hill, Shimla-171005, India. Tel: +91-177-2830946, E-mail: sushma_bio_sci@rediffmail.com 
rophy. More specifically, the purpose is to study (i) total collagen biosynthesis in skeletal muscle during $\beta$-agonist treatment, (ii) the ability of isoproterenol hydrochloride to modulate the collagen proliferation in the denervated muscle, and (iii) any alteration in the collagen fiber distribution with the application of $\beta$-agonist.

\section{MATERIALS AND METHODS}

Animal care and denervation. The entire animal care and different experimental procedures were approved by the Institutional Animals Ethics Committee of Himachal Pradesh University, Shimla-171005, India. Sexually mature male Swiss albino mice 8-10 weeks old in the range of 25-30 g were purchased from the Central Research Institute Kasauli (H.P.). They were housed in flat-bottomed polypropylene cages and maintained in the animal house of the Department of Biosciences under suitable hygienic conditions ( $16 \mathrm{~h}$ daylight; $24 \pm 2^{\circ} \mathrm{C}$ ). The mice were provided feed and water ad libitum. Normal healthy-looking mice showing no sign of morbidity were divided into four groups. Mice in the first group served as control animals. Those in the second group were divided into two subgroups. In the first subgroup, the animals received a daily dose of isoproterenol hydrochloride $(60 \mathrm{mg} / \mathrm{kg}$ body weight) for 30 days, and in the second, the animals received propranolol hydrochloride $(100 \mathrm{mg} / \mathrm{kg}$ body weight) for 30 days in addition to isoproterenol (as above). Mice in the third group were subjected to unilateral sciatectomy in the thigh region according to a procedure already described by Agarwal et al. [9] and were maintained for 30 days before being killed for study. Mice in the fourth group were denervated and were also divided into two subgroups. Those in the first subgroup received a daily administration of isoproterenol hydrochloride (as above), and those in the second subgroup received propranolol, the same as above, for 30 days following denervation, in addition to isoproterenol, also the same as above. All animals were maintained for a period of 30 days. They were killed by cervical dislocation on day 30 of postdenervation. The gastrocnemius muscle, a mixed type, was excised and processed immediately for further study.

A stock solution of isoproterenol hydrochloride and propranolol hydrochloride $(100 \mathrm{mg} / \mathrm{ml})$ was prepared in sterilized glass distilled water. Further dilutions were obtained at the time of administration, and a weekly weight record of the animals was maintained. The drugs were given orally to ensure desired and equal doses.

Dry muscle mass and total tissue proteins. The dry muscle mass of gastrocnemius muscle from mice was calculated according to Haverberg and colleagues [16], as described elsewhere [9]. A weighed amount of tissue was homogenized in nine volumes of cold distilled water. Proteins were precipitated in $10 \% \mathrm{TCA}$ at $4^{\circ} \mathrm{C}$ for $15 \mathrm{~min}$.
Precipitated proteins were separated by centrifugation at $2,000 \times g$ for $20 \mathrm{~min}$ and washed twice with ice-cold $10 \%$ TCA. The precipitate was then washed successively in (i) ice-cold $95 \%$ ethanol, (ii) ethanol:chloroform $=3: 1$, (iii) ethanol:ether $=3: 1$ (twice), and (iv) ether. The residue was dried to a constant weight in a vacuum-drying oven. The dried powder was then weighed to determine dry muscle mass. The total proteins of muscle homogenates were estimated according to Lowry and colleagues [17].

Collagen extraction. The total collagen levels in different tissues were calculated according to the hydroxyproline assay as described by Bergman and Loxley [18] with slight modifications. Weighed amounts of fine slices of different tissues $(100 \mathrm{mg})$ were digested in $5 \mathrm{M} \mathrm{HCI}$ at $100^{\circ} \mathrm{C}$ for $4 \mathrm{~h}$. Tissue homogenates were then decolorized with activated charcoal. These were gravity filtered after two minutes and rinsed with $800 \mu \mathrm{M} \mathrm{NaOH}$ and $500 \mu \mathrm{l}$ of distilled water.

Hydroxyproline assay. One hundred microliters of clear extract/supernatant was oxidized with chloramines T solution for $20 \mathrm{~min}$ at room temperature. The mixture was then heated with $p$-dimethylaminobenzaldehyde at $60^{\circ} \mathrm{C}$ for $20 \mathrm{~min}$. Full color development was reached in $15 \mathrm{~min}$. Samples were cooled and centrifuged at 3,500 $\times g$ for 10 min. Absorbance was read at $550 \mathrm{~nm}$ in a Hitachi $150-20$ Double Beam Spectrophotometer. A standard calibration curve was plotted for 4-hydroxyproline and a regression line was drawn. A conversion factor of 7.14 was employed to convert hydroxyproline into collagen (calculated from a standard curve), assuming that collagen contains 14\% 4-hydroxyproline [19].

Solubilization of collagen. Muscle tissue was homogenized in 5 volumes $(\mathrm{v} / \mathrm{w})$ of $0.1 \mathrm{M} \mathrm{NaOH}$ and extracted in the same solution for $48 \mathrm{~h}$ with gentle stirring at $5^{\circ} \mathrm{C}$ and two or three changes. The extraction was done to remove noncollagenous proteins and to prevent the effect of endogenous proteases on collagen. The residue after alkali extraction was thoroughly washed with distilled water and digested with porcine pepsin in $0.5 \mathrm{M}$ acetic acid at an enzyme/substrate ratio of $1: 20(\mathrm{w} / \mathrm{w})$ for $48 \mathrm{~h}$ at $5^{\circ} \mathrm{C}$ [20]. The collagen in the supernatant was used as pepsin-soluble collagen after centrifugation at 3,500 $\times \mathrm{g}$ for $20 \mathrm{~min}$. Pepsin-soluble collagen dialysis was done overnight against $0.2 \mathrm{M} \mathrm{Na}_{2} \mathrm{HPO}_{4}$ before electrophoresis.

Cyanogen bromide (CNBr) cleavage of insoluble residue. The pepsin-digested residue of the muscle tissue after centrifugation was dissolved in $100 \mathrm{mM} \mathrm{NH}_{4} \mathrm{CO}_{3}, \mathrm{pH} 8.0$, for $45 \mathrm{~min}$ to inactivate the pepsin before being digested in $85 \%$ formic acid containing $70 \mathrm{mg} / \mathrm{ml} \mathrm{CNBr}$. Cleavage was achieved by the method of Scott and Veis [21]. The insoluble collagen residue was determined by electrophoresis analysis, and its comparison was done with mice tail tendon collagen type-1 specific $\mathrm{CNBr}$ peptide standard. 
SDS-PAGE. Pepsin-soluble collagen chains were analyzed on $7.5 \%(\mathrm{w} / \mathrm{v})$ acrylamide gels containing $4 \%(\mathrm{w} / \mathrm{v})$ stacking gels [22]. Mice tail tendon was used as a reference standard type I collagen. The insoluble residue of the collagen from the cleaved peptides was analyzed on $12.5 \%(\mathrm{w} / \mathrm{v})$ acrylamide gels containing $4 \%$ acrylamide stacking gels. These gels were stained overnight with $0.15 \%(\mathrm{w} / \mathrm{v})$ Comassie Brilliant Blue R-250 and destained with $30 \%(\mathrm{v} / \mathrm{v})$ methanol containing $10 \%$ (v/v) acetic acid before being photographed. Quantitated electrophoresis (densitometry) was used to determine the relative amount of collagen chains.

Histopathological study. A Bouin-fixed gastrocnemius muscle section ( $6 \mu \mathrm{m}$ thick) was stained in Van Gieson and counterstained with hematoxylin to show the distribution of collagen fibers and muscle nuclei.

Statistical analysis. The results were obtained as means \pm SEM and expressed as a change in relation to normal innervated controls. The differences between control and treated groups of mice were considered significant at $* p<0.05$ by using Student's $t$-test.

\section{RESULTS}

\section{Muscle weight to body weight ratio}

Normal innervated mice exhibit gastrocnemius muscle weight to whole body weight ratio 3.94 (Fig. 1). Denervation results in further decline in the ratio 30 days postdenervation, therefore suggesting the onset of atrophy of constituent muscle fibers. However, denervated mice that received isoproterenol hydrochloride points to a partial reversal of muscle mass by day 30 . Normal innervated mice put on beta agonist therapy demonstrate a significant increase in muscle weight to body weight ratio.

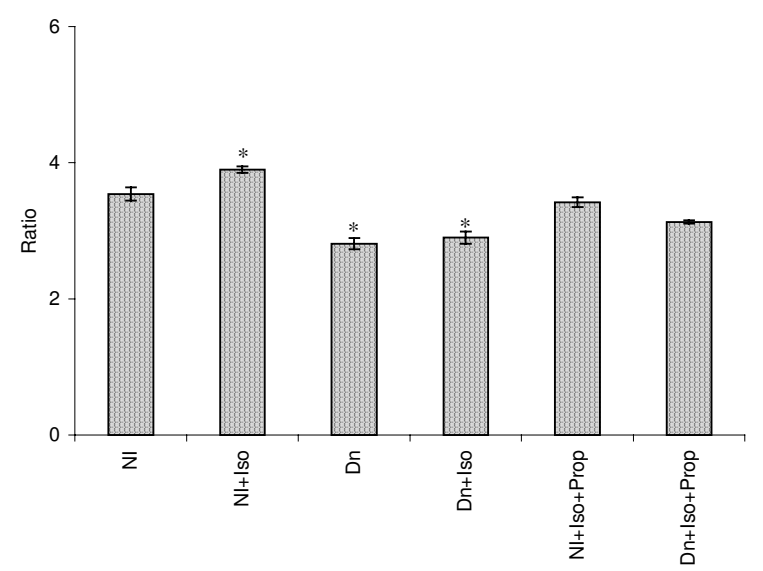

Fig. 1. Changes in muscle weight to body weight ratio (mg/ g) in gastrocnemius muscle after administration of isoproterenol hydrochloride (Iso), a $\beta$-agonist, and propranolol hydrochloride (Prop), a $\beta$-antagonist in normal innervated (NI) and denervated $(\mathrm{Dn})$ muscles. Values are mean $\pm \mathrm{SEM}$; ${ }^{*} p<$ $0.05(n=5)$.

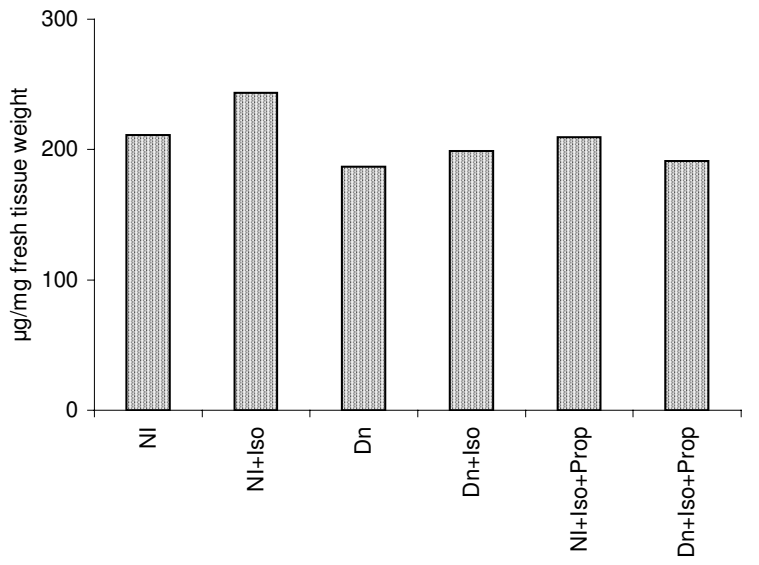

Fig. 2. Changes in dry muscle mass after the administration of beta agonist, isoproterenol (Iso), and beta antagonist propranolol (Prop) in normal innervated ( $\mathrm{NI}$ ) and denervated (Dn) mice gastrocnemius muscle. Five samples were pooled together to collect the dry muscle mass.

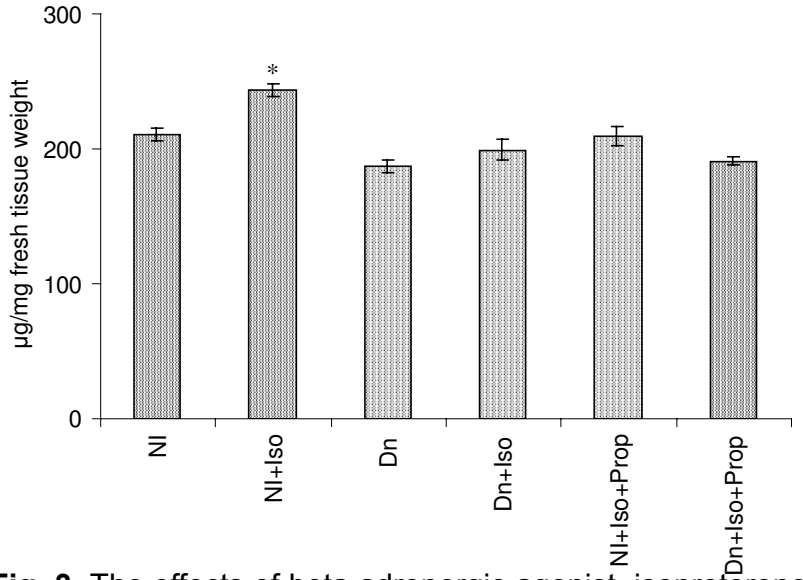

Fig. 3. The effects of beta adrenergic agonist, isoproterenol (Iso), and beta antagonist propranolol (Prop) on total tissue protein concentration in normal innervated (NI) and denervated $(\mathrm{Dn})$ mice gastrocnemius muscles. Values are mean \pm SEM; ${ }^{*} p<0.05(n=5)$.

\section{Dry muscle mass and total tissue proteins}

Alterations induced in the dry muscle mass of gastrocnemius as a result of isoproterenol hydrochloride treatment are presented in Fig. 2. Normal innervated gastrocnemius reveals a dry muscle mass of $219.3 \mu \mathrm{g} / \mathrm{mg}$ fresh tissue weight, and this increases to $258 \mu \mathrm{g} / \mathrm{mg}(n=5)$, thereby showing $17.64 \%$ improvement at day 30 after drug administration. The improvement in growth is drug specific, which is confirmed when propranolol administration inhibits this increase in dry muscle mass. Denervation results in an insignificant decline in dry muscle mass on day 30. However, propranolol administration along with isoproterenol hydrochloride further inhibits the dry muscle mass. Changes in dry muscle mass are supported by data on total tissue proteins (Fig. 3). Total tissue proteins in normal innervated gastrocnemius demonstrate an 


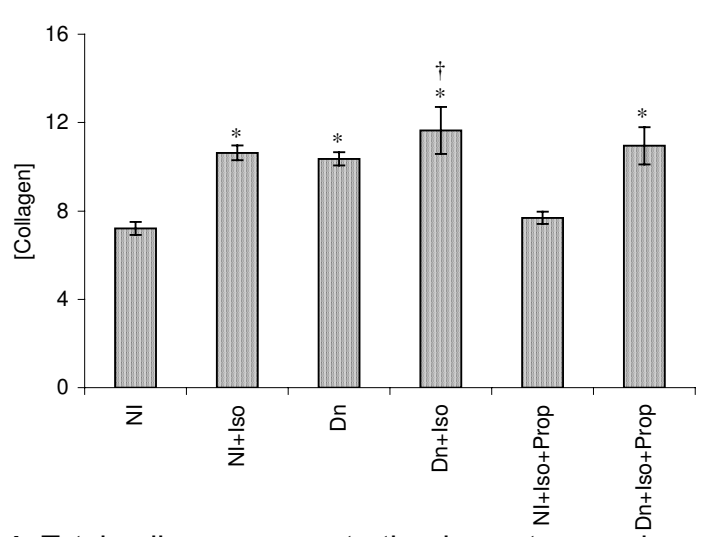

Fig. 4. Total collagen concentration in gastrocnemius muscles of mice. Collagen concentration is expressed in units of $\mu \mathrm{g} / \mathrm{mg}$ fresh tissue weight. A heavy increase in collagen concentration is evident in normal innervated $(\mathrm{NI})$ and denervated (Dn) muscles after isoproterenol hydrochloride (Iso) administration. Collagen concentration in propranololadministrated mice remain nearest to their controls. Values are mean $\pm \mathrm{SEM}$; ${ }^{*} p<0.05(n=5), \uparrow p<0.05$ between Dn and $\mathrm{Dn}+$ Iso.

increase of $15.32 \%$ following isoproterenol hydrochloride treatment. The onset of denervation induced atrophy in gastrocnemius muscle, and its amelioration by beta agonist is also confirmed from the measurement of total tissue proteins.

\section{Collagen changes}

Collagen, a fibrous protein and a constituent of noncontractile connective tissue, is an important structural and functional element in skeletal muscle organization. Hydroxyproline assay of gastrocnemius muscle (Fig. 4) from normal innervated mice depicted a collagen concentration of $7.21 \pm 0.292 \mu \mathrm{g} / \mathrm{mg}$ fresh tissue weight (Fig. 4). The administration of isoproterenol hydrochloride shows more than a $47 \%$ increase in collagen, which became established at day 30 posttreatment. The drug-induced proliferation of collagen is confirmed from its inhibited levels in the presence of propranolol both in normal innervated $(7.69 \pm 0.275 \mu \mathrm{g} / \mathrm{mg})$ fresh tissue weight and denervated gastrocnemius $(10.95 \pm 0.836 \mu \mathrm{g} / \mathrm{mg})$ fresh tissue weight on day 30. Collagen levels are comparable to those obtained from both control innervated mice receiving drug and denervated tissue in the absence of drug (Fig. 4).

Denervation results in a progressive and temporal increase in the collagen content of gastrocnemius muscle (Fig. 4). Thus the muscle exhibits a collagen level of $10.36 \pm 0.229 \mu \mathrm{g} / \mathrm{mg}$ fresh tissue weight on day 30 postdenervation. This amounts to an increase of $44 \%$ compared to normal innervated control muscle. The administration of isoproterenol hydrochloride to denervated mice fails to inhibit collagen proliferation; instead, it further adds to already proliferating noncontractile element ( $\dagger p<$ $0.05 ; n=5)$. Denervated gastrocnemius thus documents a
A

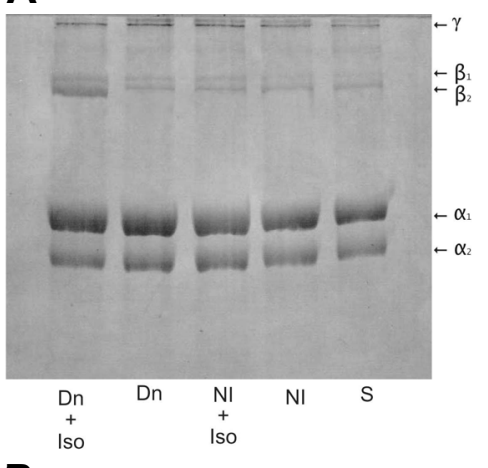

B

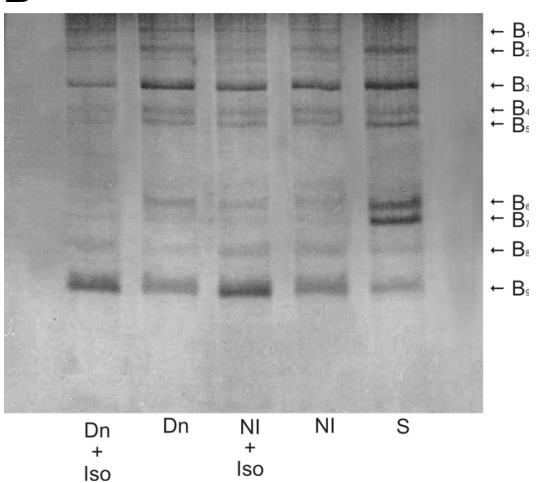

Fig. 5. SDS-PAGE of pepsin-solubilized collagen (A) and CNBr-treated pepsin insoluble collagen (B) from normal innervated ( $\mathrm{NI}$ ) and denervated (Dn) muscles after isoproterenol hydrochloride (Iso) administration. $\mathrm{S}=$ Standard collagen from mice tail artery.

collagen concentration of $11.64 \pm 0.060$ on day 30 in the presence of beta agonist. These figures suggested an amplified proliferation of collagen in denervated tissue in the presence of isoproterenol by $12.35 \%$. Normal innervated and denervated gastrocnemius, which receives isoproterenol hydrochloride and propranolol, shows a collagen concentration of $7.69 \pm 0.275 \mu \mathrm{g} / \mathrm{mg}$ fresh tissue weight and $10.95 \pm 0.836 \mu \mathrm{g} / \mathrm{mg}$ fresh tissue weight, respectively, on day 30 .

\section{SDS-PAGE of pepsin soluble collagen}

An SDS-PAGE of pepsin-digested collagen from all samples results in five protein bands (Fig. 5A) from origin point to migration side $\left(\gamma, \beta_{1}, \beta_{2}, \alpha_{1}\right.$, and $\left.\alpha_{2}\right)$. The collagen type I molecule consists of two identical chains, called $\alpha_{1}$, hydrogen bonds to $\alpha_{1}$ each other and to a third chain with a different amino acid sequence, termed $\alpha_{2}$. This collagen therefore is given the molecular formula $\left[\alpha_{1}\right]_{2} \alpha_{2}$. Collagen type III represented with the formula $\left[\alpha_{1}\right]_{3}$ have three identical chains of $\alpha_{1} . \beta_{1}$ and $\beta_{2}$ components are the cross-links indicating that all samples are extensively cross-linked. Densitometric analysis shows a small decrease in the $\beta$ component in normal innervated muscle receiving drug and control denervated muscle. However, denervated gastrocnemius muscle treated with $\beta$-agonist 
Table 1. Changes in $\alpha$ and $\beta$ chains of pepsin-solubilized collagen during isoproterenol hydrochloride (Iso) administration in normal innervated $(\mathrm{NI})$ and denervated $(\mathrm{Dn})$ gastrocnemius muscles. [Values are means \pm SEM of 6 samples in each group.]

\begin{tabular}{lrrrr}
\hline \multirow{2}{*}{ Muscle } & \multicolumn{3}{c}{ Percent of total } & \multirow{2}{*}{$\alpha / \beta$ ratio } \\
\cline { 2 - 4 } $\mathrm{NI}$ & $\alpha_{1}$ & $\alpha_{2}$ & $\beta$ & 3.715 \\
$\mathrm{NI}+$ Iso & $50.148 \pm 1.48$ & $28.37 \pm 2.69$ & $21.135 \pm 1.89$ & 4.120 \\
$\mathrm{Dn}$ & $51.42 \pm 3.62$ & $28.99 \pm 1.15$ & $19.486 \pm 0.89$ & 4.047 \\
$\mathrm{Dn}+$ Iso & $51.28 \pm 3.82$ & $28.83 \pm 1.82$ & $19.79 \pm 2.80$ & 3.350 \\
\hline
\end{tabular}

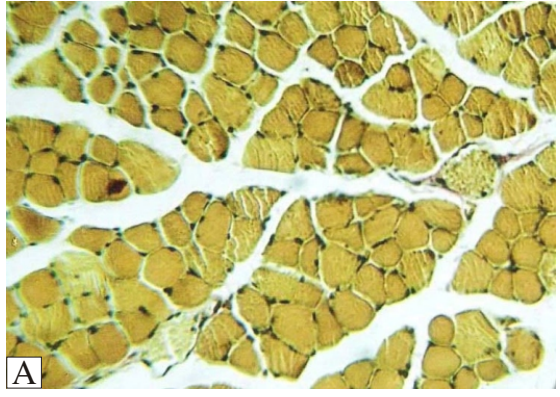

Fig. 6. Histopathological examination of gastrocnemius muscle after Van Gieson staining for collagen fibers. Normal innervated muscle of control mice reveals an undetectable amount of collagen $(\mathbf{A})$. The collagen-infiltrated region of mice from normal innervated muscle after isoproterenol administration in epimysium (B) and perimysium (C). Denervated control muscle showing collagen proliferation in epimysium (D) and around the adventitia tissue of blood vessels (E). $\times 275$.
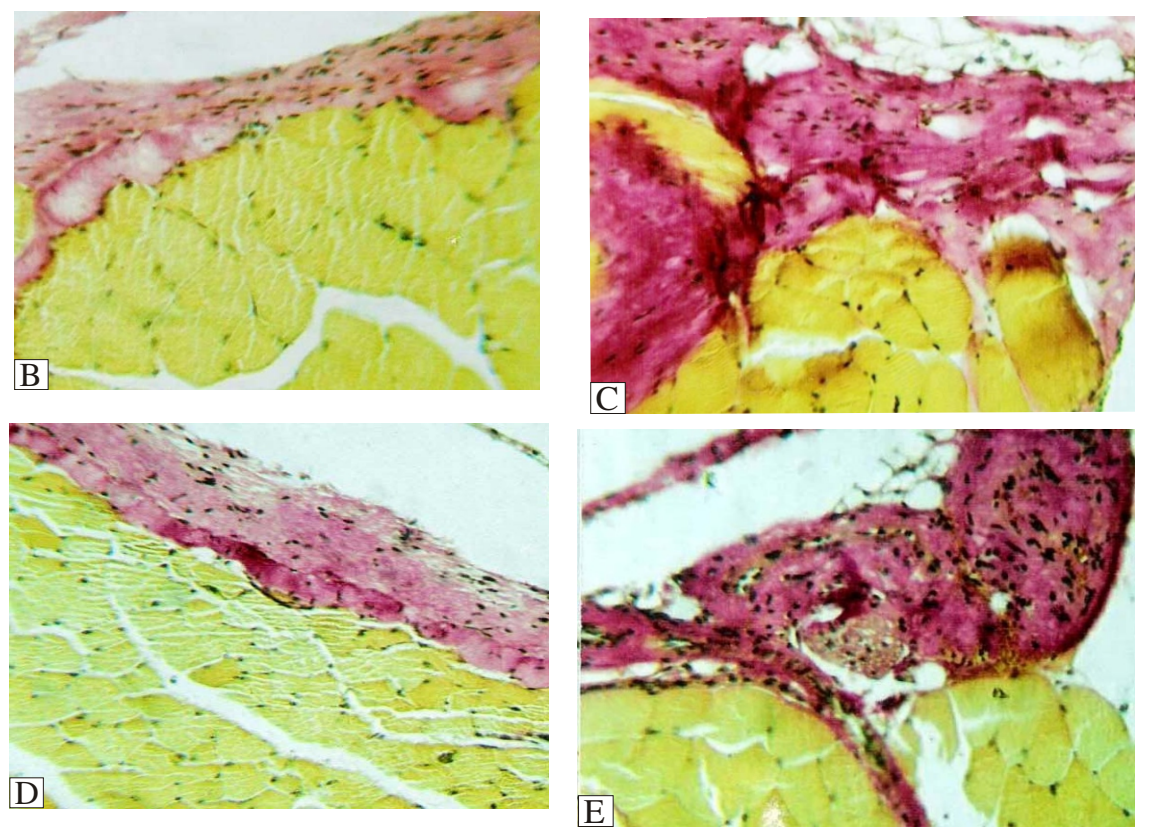

isoproterenol exhibited a small increase in the $\beta$ component. There is no significant change in the $\alpha_{1}$ component in normal innervated muscle receiving drugs and normal denervated muscle. However, denervated muscle receiving drugs results in a significant decrease in the $\alpha_{1}$ (Table 1) component. The image analysis shows that the percent of content in the $\alpha_{2}$ component in all samples remains comparable with one another. The ratio of the percent of content $(\alpha / \beta)$ of the control, the innervated + drug, the denervated drug, and the denervated + drug shows 3.715 , $4.12,4.047$, and 3.35 respectively.

\section{SDS-PAGE of insoluble residue of collagen}

CNBr-digested insoluble collagen residues (Fig. 5B) show nine bands of peptides that are almost comparable with all muscle samples. Mice tail tendon treated with $\mathrm{CNBr}$ is used as reference. Peptide bands of three samples, gastrocnemius control, innervated + drug, and denervated control are comparable with one another, except for band $\mathrm{B}_{9}$ in innervated + drug and $\mathrm{B}_{6}$ in denervated control. However, quantitative differences in the polypeptide organization of collagen in denervated mice treated with isoproterenol hydrochloride are distinguishable. The denervated gastrocnemius muscle treated with $\beta$-agonist iso- proterenol shows a relative decrease in the peptide band intensity, except for band $\mathrm{B}_{9}$.

\section{Histopathological studies}

Van Gieson staining, employed to determine qualitative changes in noncontractile elements, demonstrated a collagen increase, especially around blood capillaries and in those regions in muscles that show myonecrosis. Histopathological slides exhibit the extensive proliferation of collagen fibers in all types of muscle, except control muscle (Fig. 6A). The collagen in control muscle tissue reveals its restricted distribution to either the outer region or covering the adventitia of different blood vessels. The collagen fibers stain more in the epimysium layer (Figs. 6B, $6 \mathrm{D}$, and $7 \mathrm{~A}$ ) and around the blood vessels adventitia tissue (Figs. 6E and 7B) as a darkly stained layer in all sections in comparison to control muscle. In the perimysium region, collagen proliferation is mostly restricted toward the blood vessels. However, denervated gastrocnemius treated with the $\beta$-agonist shows a heavy collagen proliferation also in the endomysium region (Fig. 7C). 

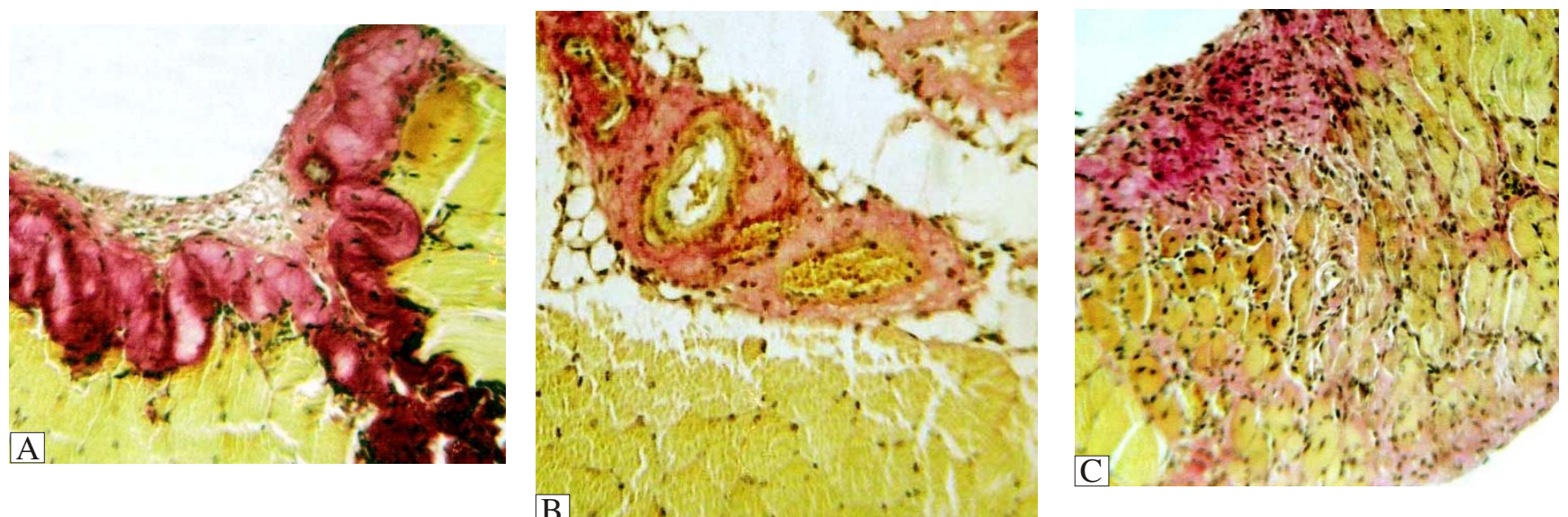

Fig. 7. Histopathological slides of isoproterenol-treated denervated muscle resulted in abundant collagen infiltration in the epimysium (A), in the adventitia tissue of blood vessels, $(\mathbf{B})$ and in the endomysium region $(\mathbf{C}) . \times 275$.

\section{DISCUSSION}

A chronic administration of the $\beta$-adrenoreceptor agonist isoproterenol hydrochloride remolds the extracellular matrix protein collagen. A remodeling of collagen in the extracellular matrix as a result of $\beta$-agonist, isoproterenol hydrochloride is confirmed with hydroxyproline assay, SDS-PAGE of pepsin soluble collagen, SDS-PAGE of $\mathrm{CNBr}$-treated insoluble residue of collagen, and Von Gieson staining of collagen fibers in muscle sections. However, what is important and interesting is a significant collagen proliferation accompanying hypertrophy of normal innervated muscles and a stepped-up collagen proliferation in fibrosis-typified denervated muscle. $\beta$-adrenoreceptor agonists equally cause the hypertrophy $[23,24]$ of normal innervated mice skeletal muscle and ameliorate tissue denervation atrophy. The ability of $\beta$-agonists promotes skeletal muscle hypertrophy, which is confirmed from raised total tissue protein level, dry muscle mass, and muscle-weight-to-body-weight ratio. An increase of more than $15 \%$ to $16 \%$ in muscle protein and an almost equal acceleration in dry muscle mass $(17 \%)$ on day 30 following chronic drug administration is testimony to stimulated muscle growth in normal innervated mice. Results further suggest that normal innervated mice muscle growth outscores body weight.

$\beta$-Adrenoreceptor agonist effects are restricted not only to normal innervated muscle, but have been reported in different diseased states characterized by an atrophy of constituent muscle cells. This includes also denervation atrophy [9, 25], aging and senescence [26], and muscle dystrophy. These drugs restore the original balance of equilibrium in favor of elevated protein biosynthesis and a decreased degradation so that atrophy is ultimately replaced by normal-looking cells. The drug, isoproterenol hydrochloride, used in the present study is capable of restoring original structural and functional organization of denervated muscle. Therefore these drugs are equated as sympathomimetic substances capable of mimicking the function of normal innervations in a variety of vertebrate's skeletal muscles [9, 27].

Traditionally adrenoceptor agonists are anabolic agents whose therapeutic potential lies in their ability to increase nitrogen retention and to accelerate protein biosynthesis. The measurement of dry muscle mass and total tissue proteins was employed as an indicator of the retention of $\mathrm{N}$ content or of levels that point to a drug-induced hypertrophy in gastrocnemius muscle. The gross fractional synthesis rate for collagen is about $5 \%$ /day in the skeletal muscle of young rats [28], whereas the fractional synthesis rate for total protein is about $11 \%$ to $15 \%$ a day [29]. The effect of isporoterenol administration is not limited to intracellular proteins; it has equal effects on extracellular protein collagen. A hydroxyproline assay of collagen showed collagen proliferation in innervated gastrocnemius because of $\beta$-agonist. A common assumption in the studies of collagen turnover is measured by hydroxyproline derived from collagen. Although it is known that some other proteins also contain hydroxyproline, their contribution to the total hydroxyproline content of a tissue is probably negligible [28]. $\beta$-adrenergic agonists proliferate collagen, which is supported equally by Duncan et al. [5], who showed an increase in collagen infiltration (possibly reparative) in the heart of chronic clenbuterol administration (Patiyal and Katoch, in press).

Denervation atrophy in itself is a pathophysiological condition characterized by collagen proliferation. Increased collagen synthesis most likely has a key role in progressive fibrosis [31]. The accumulation of collagen in the ECM in inflammatory myopathies is mediated by increased gene expression and activities of enzymes participating in the posttranslational modifications of collagen [31]. Such diseases as diabetes, may have a role in the muscular ECM remodeling; diabetes is known to cause increased type IV collagen expression in nerves and renal microvessels $[31,32]$. Our present study also shows that denervation enhances the proliferation of noncontractile 
extracellular matrix element collagen. Collagen proliferation no doubt is also observed in normal innervated muscle. However, what is surprising is an augmented proliferation of collagen in denervated mice after the treatment of isoproterenol. $\beta$-adrenoreceptor agonist does in fact cause the proliferation of collagen in heart ventricles. The proliferation of collagen as a result of drug administration in denervated muscle fibrosis is equally supported by the present investigation of histopathological studies of muscle sections stained for collagen fibers. The deposition of proliferated collagen in normal and denervated muscle is found to be mostly around the perimysium layer of muscle and around the adventitia tissue of blood vessels. An accumulation of collagen around the muscle cells and capillaries is physiologically disadvantageous, since it complicates the transportation of nutrients and cellular excreta between blood and cells and complicates the pathology of the diseases even further. In control innervated mice, collagen is restricted to the outer ring and adventitia of blood vessels; isoproterenol-treated animals show collagen infiltration, redistribution, and increased deposition in the muscle tissue of the adventitia of blood vessels, outer region (epimysium), and certain outer localized areas [5]. Denervated muscle tissue treated with isoproterenol hydrochloride in the present study shows a heavy proliferation of collagen in also in endomysium, which is absent in all other muscle tissues. The augmentation in collagen proliferation in denervated muscle is also shown by hydroxyproline assay, which is probably due to the deposition of collagen in the endomysium region other than perimysium and epimysium. This shows a remodeling of collagen synthesis or degradation that is more prominent in denervated muscle after drug administration.

The SDS-PAGE of pepsin soluble collagen from all four samples shows five bands. In the skeletal muscle, collagen types I and III are dominant collagen types represented by the formulas $\left[\alpha_{1}\right]_{2} \alpha_{2}$ and $\left[\alpha_{1}\right]_{3}$, respectively. The cross-link between collagen fibrils is largely responsible for the tensile strength attributed to collagen, thus altering tissue structure and function. The densitometric analysis of cross-linking $\left(\beta_{1}\right.$ and $\left.\beta_{2}\right)$ shows an increase in band intensity in denervated muscle treated with isoproterenol. A decrease in the percent content is also recorded in the $\alpha_{1}$ chain of denervated muscle put on isoproterenol therapy. Thus isoproterenol alters the metabolic activity of the collagen fibrils and remolds collagen fibrils. The remolding capacity of the drug is not seen as much in normal innervated muscle of mice treated with a drug. This may be because after denervation, the muscles become more sensitive to $\beta$-adrenoceptor agonists.

The CNBr treatment of pepsin-insoluble collagen further supports the remodeling of collagen in denervated muscle more prominently after isoproterenol therapy, which results in a decrease in pepsin-insoluble collagen.
The decrease in insoluble collagen with altered physiological composition as a result of $\beta$-agonist treatment is thus a pathophysiological indication of drug-induced fibrosis in denervated muscle. The synthesis and degradation of extracellular matrix proteins, including collagen, are in a state of reversible equilibrium in normal myocardium [33]. The observed beta agonist induced collagen proliferation is therefore either because of its reduced degradation or because of an elevated biosynthesis.

Collagen proliferation is controlled by the intracellular collagenases, such as matrix metalloproteinases (MMPs). A recent investigation from our laboratory showed that $\beta$ adrenoceptor agonist clenbuterol downregulates the MMP-9 in mice left ventricle, which is probably responsible for collagen proliferation in mice hearts [34]. Because of the collagen proliferation, it is confirmed that collagenase activity must be suppressed in denervated muscle fibrosis. But what happens to denervated muscle treated with isoproterenol, which further augments collagen proliferation, still remains to be confirmed.

Thanks are due to the Council of Scientific and Industrial Research (CSIR), New Delhi, for the award of a Junior Research fellowship to one of the authors (RK). This work is great tribute to late Prof. Surender S. Katoch Himachal Pradesh University, Shimla, India.

\section{REFERENCES}

1. Petrou M, Clarkes Morrison K, Bowles C, Dunn M, Yacoob M. Clenbuterol increase stroke power \& contractile speed of skeletal muscle for cardiac assist. Circulation. 1999:99:713-20.

2. Deleke FT, Desmet N, Debackere $M$. The abuse of doping agents in competing body builders in Flanders (1988-1993). Int J Sports Med. 1995;16:66-70.

3. Dumestre Toulet V, Cirimele V, Ludes B, Gromb S, Kintz P. Hair analysis of seven body builders for anabolic steroid, ephedrine \& clenboterol. J Forensic Sci. 2002;47:211-4.

4. Chen KD, Always SE. A physiological level of clenbuterol does not prevent atrophy or loss of force in skeletal muscle of old rats. J Appl Physiol. 2000;89:606-12.

5. Duncan ND, Williams DA, Lynch GS. Deleterious effects of chronic clenbuterol treatment on endurance and sprint exercise performance in rats. Clin Sci. 2000;98:339-47.

6. Ingalls CP, Barnes WS, Smith SB. Interaction between clenbuterol and run training: effects on exercise performance \& MLC isoforms content. J Appl Physiol. 1996;80:785-801.

8. Plant DR, Kearns CF, McKeever KH, Lynch GS. Therapeutic clenbuterol treatment does not alter $\mathrm{Ca}^{2+}$ sensitivity of permeabilized fast muscle fibres from exercise trained or untrained horses. J Muscle Res Cell Motil. 2003;24:471-6.

9. Agrawal S, Thakur P, Katoch SS. Beta-adrenoceptor agonists, clenbuterol and isoproterenol retard denervation atrophy in rat gastrocnemius muscle: Use of 3methylhistidine as a marker of myofibrillar degeneration. Jpn J Physiol. 2003:53:229-37.

10. Zeman RJ, Ludermann R, Etlinger J. Clenbuterol, a $\beta_{2}$-agonist, retards atrophy in denervated muscle. Am J Physiol. 1987;252:E152-5.

11. Aumailley M, Gayraud B. Structure and biological activity of the extracellular matrix. J Mol Med. 1998;76:253-66.

12. Melo F, Carey DJ, Brandan E. Extracellular matrix is required for skeletal muscle differentiation but not myogenin expression. J Cell Biochem. 1996;62:227-39.

13. Borg TK, Caulfield JB. Morphology of connective tissue in skeletal muscle. Tissue Cell. 1980;12:197-207.

14. Light ND. In:The role of collagen in determining the texture of meat. New York, NY: Advances in Meat Research; 1987. Vol 4,. p. 87-107.

15. McCormick RJ, Musch TI, Bergman BC, Thomas DP. Regional differences in LV 


\section{R. KUMAR and S. SHARMA}

collagen accumulation and mature cross-linking after myocardial infarction in rats. Am J Physiol Heart Circ Physiol. 1994;266:H354-9.

16. Haverberg L, Omstedtm MPT, Munro HN, Young VR. N-methylhistidine content of mixed proteins in various rat tissues. Biochem Biophys Acta. 1975;405: 67-71.

17. Lowry OH, Rosebrough MJ, Farr AL, Randall RJ. Protein measurement with folin phenol reagent. J Biol Chem. 1951;193:265-75.

18. Bergman I, Loxley R. Two improved and simplified methods for the spectrophotometric determination of hydroxyproline. Anal Chem. 1963;35:196165

19. Brilla CG, Zhau G, Matsubara L, Weber KT. Collagen metabolism in cultured adult rat cardiac fibroblasts: response to angiotensin II and aldosterone. J Mol Cell Cardiol. 1994;26:809-20.

20. Mizuta S, Tanaka T, Yoshinaka R. Comparison of collagen types of arm and mantle muscles of the common octopus (Octopus vulgaris). Food Chem. 2003;81:527-32.

21. Scott PG, Veis $A$. The cyanogens bromide peptides of bovine soluble \& insoluble collagens connective. Tissue Res. 1976;4:107-16.

22. Laemmli UK. Cleavage of structural proteins during the assembly of the head of bacteriophage $T_{4}$. Nature. 1970;227:680-5.

23. McLennan P, Edwards R. Effects of clenbuterol and propranolol on muscle mass: evidence that clenbuterol stimulates muscle adrenoceptors to induce hypertrophy. Biochem J. 264: 1989;573-9.

24. Palmer R, Delday MI, McMillan D, Noble B, Bain P, Maltin CA. Effects of cyclooxygenase inhibitor, fenbufen, on clenbuterol induced hypertrophy of cardiac and skeletal muscles of rats. Br J Pharmacol. 1990;101:835-8.
25. Katoch SS, Sharma K. Clenbuterol treatment stimulates cell proliferation in denervated chick gastrocnemius muscle. Ind J Exp Biol. 2004;42:770-5.

26. Carter W, Dang A, Foss F, Lynch M. Effect of clenbuterol on muscle mass, body composition and recovery from surgical stress in senescent rats. Metabolism. 1991;40:855-60.

27. Kumar S, Sharma S, Katoch SS. Early onset of the maximum protein anabolic effect induced by isoproterenol in chick skeletal and cardiac muscle. Acta Physiol Hung. 2003;90:57-67.

28. Mays PK, McAnulty RJ, Campa JS, Laurent GJ. Age related changes in collagen synthesis and dedradation in rat tissue. Biochem J. 1991;276: 307-13.

29. Goldspink DF, Morton AJ, Loughna P, Goldspink G. The effect of hypo kinesia and hypodynamia on protein turnover and the growth of four skeletal muscles of the rats. Pflügers Arch. 1986;407:333-40.

30. Myllylä R, Myllylä VV,Tolonen U, Kivirikko KI. Changes in collagen metabolism in diseased muscle. I. Biochemical studies. Arch Neurol. 1982;39:752-5.

31. Bradly JL, King RHM, Muddle JR, Thomas PK. The extracellular matrix of peripheral nerve in diabetic poly neropathy. Acta Neuropathol. 2000;99:539-46.

32. Tsilibary EC. Microvascular basement membranes in diabetes mellitus. J Pathol. 2003;200:537-46.

33. Tyagi SC, Kumar S, Reddy SR, Reddy HK, Voelbar DJ, Janiski JS. Extracellular matrix regulation of metalloproteinase and anti proteinase in human heart fibroblast cells. J Cell Physiol. 1996;167:137-47.

34. Patiyal SN, Katoch SS. $\beta$-adrenoceptor agonist clenbuterol down-regulates matrix metalloproteinases (MMP-9) and results in an impairment of collagen turnover in mice left ventricle. Jpn J Physiol. 2005;55:165-72. 